\title{
On long-term predictions of the maximum sunspot numbers of solar cycles 21 to 23
}

\author{
K. J. Li ${ }^{1,2}$, H. S. Yun ${ }^{1}$, and X. M. Gu ${ }^{2,3}$ \\ 1 Astronomy Program, SEES, Seoul National University, Seoul 151-742, Korea \\ ${ }^{2}$ Yunnan Observatory, CAS, Kunming 650011, National Astronomical Observatories, PR China \\ 3 United Laboratory of Optical Astronomy, CAS, PR China
}

Received 10 September 2000 / Accepted 30 November 2000

\begin{abstract}
We have collected a set of predicted values of maximum sunspot numbers of solar cycles 22 and 23 published in the literature and examined the characteristics of predictions made by various methods. The precursor methods are found to be always superior to other prediction methods. The maximum sunspot number of solar cycle 23 is here inferred to be about 162 .
\end{abstract}

Key words. Sun: activity - Sun: predictions

\section{Introduction}

The cyclical behaviour of solar activity, in particular the 11-year sunspot cycle, is now a well-known property of the Sun (Hong 1992). Apart from providing information of the physical process inside the Sun, solar activity gives rise to variations of the solar-terrestrial system, for example, solar activity affects and even controls the physical condition of the Earth upper atmosphere and the space environment around the Earth as well. Practical experience reveals that there should be some relationship between solar activity and geophysical phenomena, such as large-scale and long-term meteorological and hydrological changes. In addition to a wide range of scientific interests, there are also several practical and commercial reasons why it is important to know what the magnitude of a forthcoming sunspot maximum is likely to be. For example, knowledge of the average level of solar activity is of vital importance to radio communication engineers and to space science technologists who are concerned about the lifetime of artificial satellites (Brown 1990). The study of solar-terrestrial relations, which have not yet been clearly known up to the present, is obviously of great practical significance for the existence of human beings, which makes predictions of the magnitude of a forthcoming sunspot maximum even more important ( $\mathrm{Li} \& \mathrm{Gu} 1999$; Wang 1992).

Since Yule (1927) first proposed a technique called an autoregressive method, a great variety of techniques have been introduced to predict the magnitude of sunspot

Send offprint requests to: K. J. Li,

e-mail: kejunli@netease.com activities. They can be divided into two large groups, one of which relies solely on solar activity data (hereafter called Group A) and the other utilizes not only solar activity data but also some additional external information such as solar-geophysical data (hereafter called Group B) (Li \& Gu 1999; Hanslmeier et al. 1999). The latter approach often refers to precursor methods. In a Boulder Report McIntosh et al. (1979) presented a histogram of thirty-eight predictions made by numerous workers for the maximum sunspot number of solar cycle 21 but without references. Brown divided the thirty-eight predictions into two groups, one of which comprised predictions made by precursor methods, and the other made by the so-called statistical methods. It is interesting to note that the predictions based on precursor methods form a reasonably consistent group and the resulting predictions are found to fall within $\pm 20 \%$ of the observed value. However, almost all of the other predictions clearly underestimated the observed value. Brown \& Simon (1986), Brown (1989), Kane (1992), and Denkmayr (1996) have collected predictions of the maximum sunspot number of solar cycle 22 . In the present study, we have collected as many events as possible to make more accurate predictions of the maximum sunspot numbers of solar cycle 22 through cycle 23. Finally, we will make a few comments on long-term predictions of maximum sunspot numbers.

\section{Predictions for the size of solar cycle 22}

Since the period of the solar cycle varies relatively very little from cycle to cycle, the prediction of the timing of a subsequent sunspot maximum does not pose such a 


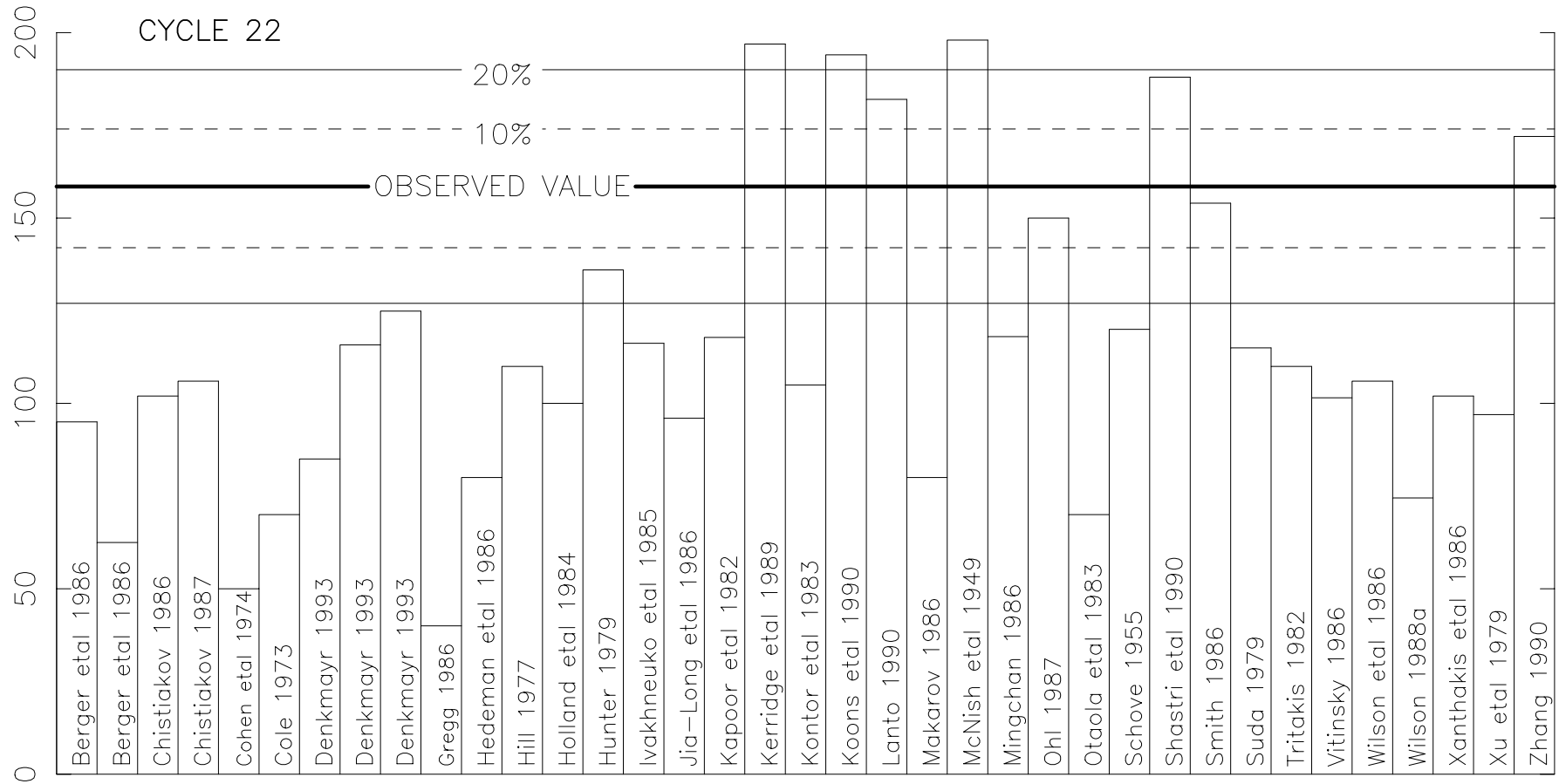

Fig. 1. Predictions of the maximum sunspot number of solar cycle 22 in Group A. The bold horizontal line represents the observed value of 157.6 and the two dashed lines are the upper and lower bounds of $\pm 10 \%$ of the observed value respectively. The two thin solid lines refer to the bounds of $\pm 20 \%$

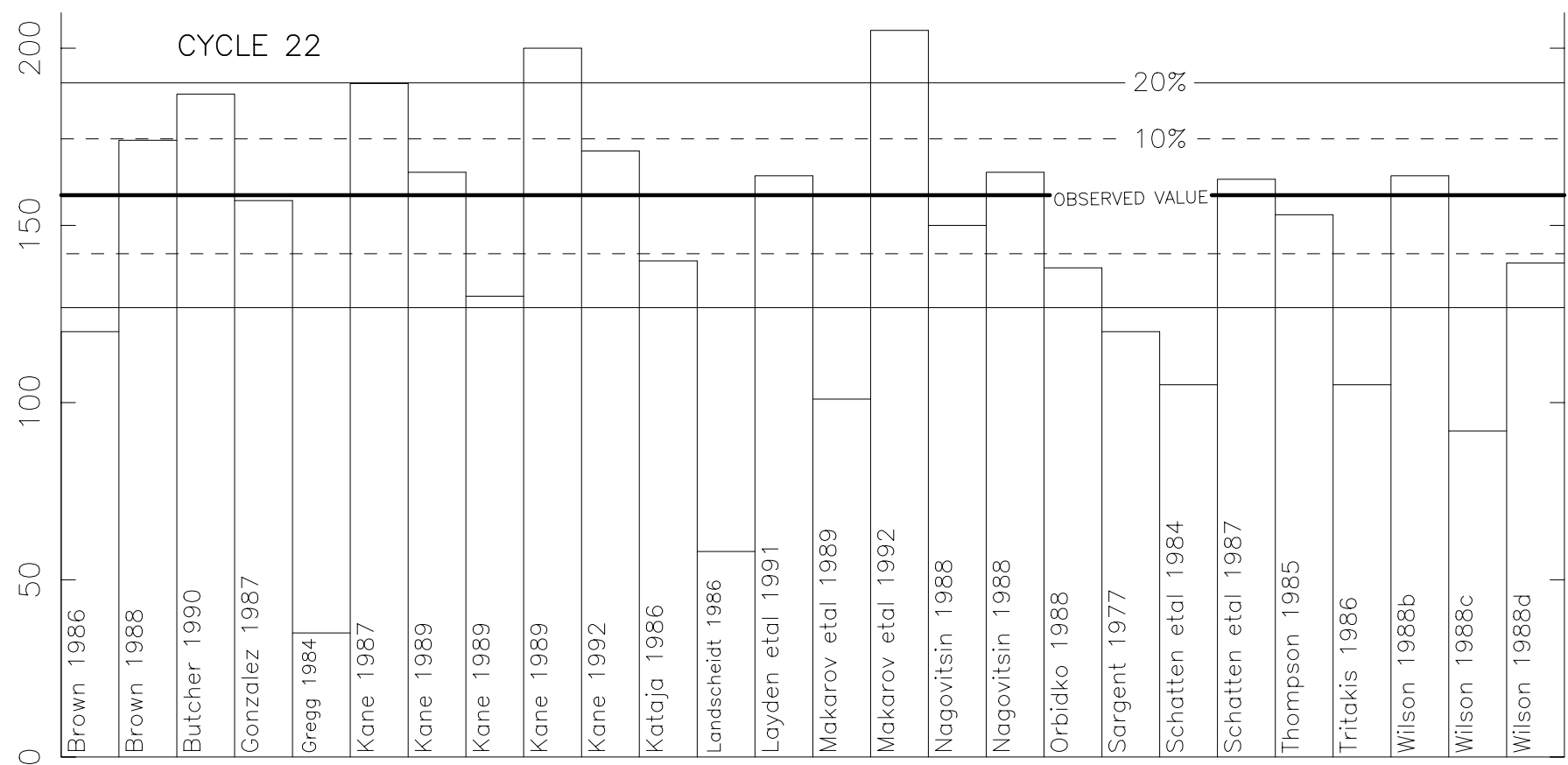

Fig. 2. Predictions of the maximum sunspot number of solar cycle 22 in Group B. All of the horizontal lines refer to the same as in Fig. 1

problem as the prediction of the magnitude of maximum sunspot numbers (Brown 1990).

Solar cycle 22 began in 1986 and peaked in 1989 . In the present study we have collected 63 predicted values of the maximum sunspot number of solar cycle 22. Among them, 37 values belong to Group A (see Fig. 1) and the other 26 to Group B (see Fig. 2). Only 2 values in Group B were obtained by using data inherent to solar system geometry such as the configuration of planets with respect to the Sun. As seen from Fig. 1, only three out of 37 values fall within $\pm 10 \%$ of the observed value 157.6 (annual mean) and only 6 values, within $\pm 20 \%$. This clearly demonstrates 


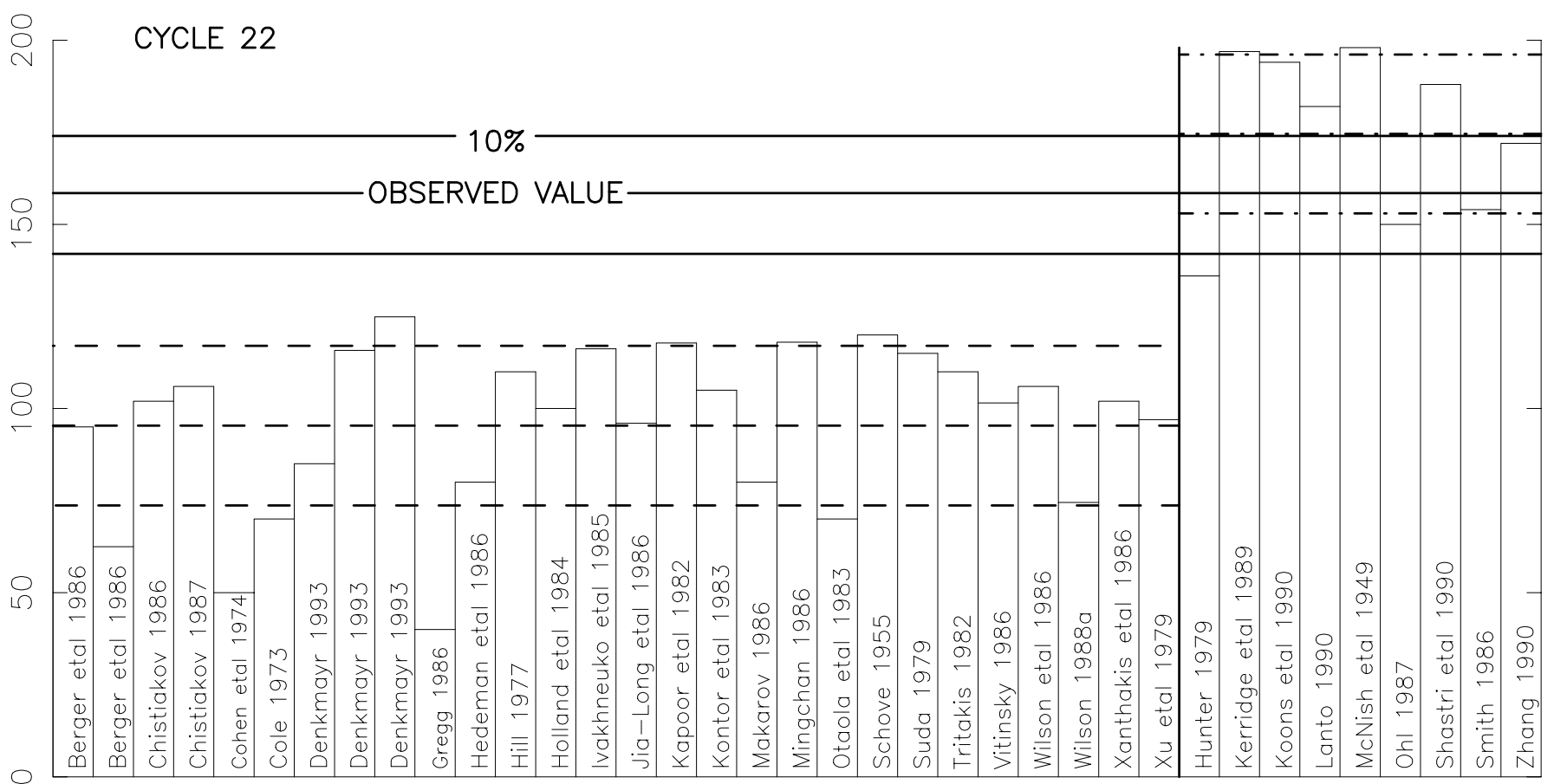

Fig. 3. Two parts of predictions of the maximum sunspot number of solar cycle 22 in Group A

that the non-precursor methods applied to Group A is questionable in general. The smallest 2 values shown in Fig. 2 are located far from the observed value so that the methods based on solar system geometry data may be regarded as being unsuccessful. Out of the remaining 24 values in Group B, ten values fall within $\pm 10 \%$ of the observed value, and as many as 16 values, within $\pm 20 \%$. Although the average of the 24 values is found to be $\overline{R_{\mathrm{m}}}=$ 149.9 close to the observed one, the variance $\sigma=30.92$ is large.

The values of Group A in Fig. 1 can also be divided into two parts. Here we have taken eighty percent of the observed value as a critical value and have used it as a reference of the division (i.e the lower horizontal thin solid line of Fig. 1). Among the 37 values, 28 values go into one part with an average $\overline{R_{\mathrm{m}}}$ of 95.36 and a variance $\sigma$ of 21.66, while only 9 values are classified into the other part with an average $\overline{R_{\mathrm{m}}}$ of 174.54 and a variance $\sigma$ of 21.54. Three lines representing the average $\overline{R_{\mathrm{m}}}$ and the upper and lower bounds of $\overline{R_{\mathrm{m}}} \pm \sigma$ are drawn in Fig. 3, where the horizontal dashed lines refer to one part with lower values and the horizontal dashed and dotted lines to the other part, respectively. The observed value and the upper and lower bounds of $\pm 10 \%$ are also included in the figure. As seen from Fig. 3, the averages taken over each of the two groups are located outside the upper and lower bounds of the observed value; especially the boundary (or interval) of the lower part is far from the observed value. The figure demonstrates that for solar cycle 22, Group A either overestimates or underestimates the maximum sunspot number, but most of the predictions (i.e., 28 cases out of the total of 37) underestimates the maximum. For solar cycle 21, on the other hand almost all of the predictions in Group A underestimate the observed maximum sunspot number. Figure 3 also shows that the overestimated predictions come in the later period of solar cycles, which yields an outlook of earlier anticipations of a very small maximum which ends up with an abnormally high maximum, viz. an early forecast of a low maximum has a high percentage probability of being an underestimate.

\section{Predictions for the size of solar cycle 23}

The starting time of solar cycle 23 is generally regarded as May 1996 although Harvey \& White (1999) claim that the minimum between cycle 22 and cycle 23 occurred in September 1996. Since then, solar cycle 23 has progressed for more than 4 years. The Sun is now in a period of rather high activity, but at present we do not know whether the maximum solar activity has occurred or not. A number of predictions of the maximum solar activity have been suggested for the cycle 23 . Here we have collected 48 predictions, among which 17 were obtained by using the precursor methods and the other 31 were classified into Group A.

Predictions of Group A can also be divided into two parts by taking the observed value of the solar cycle 22 as a critical dividing criterion. As a result, 16 cases with lower values were put into one part and the remaining 15 cases with larger values into the other. All predictions of the two parts are presented in Fig. 4, while those of Group B are given in Fig. 5. In Fig. 4, we may note an unexpectedly large gap between the two parts of Group A. The average $\overline{R_{\mathrm{M}}}$ of the first part is 107.9 with a large variance $\sigma$ of 27.9. The average $\overline{R_{\mathrm{M}}}$ of the second part is 202.1 with a rather small variance $\sigma$ of 14.9. Three lines representing 


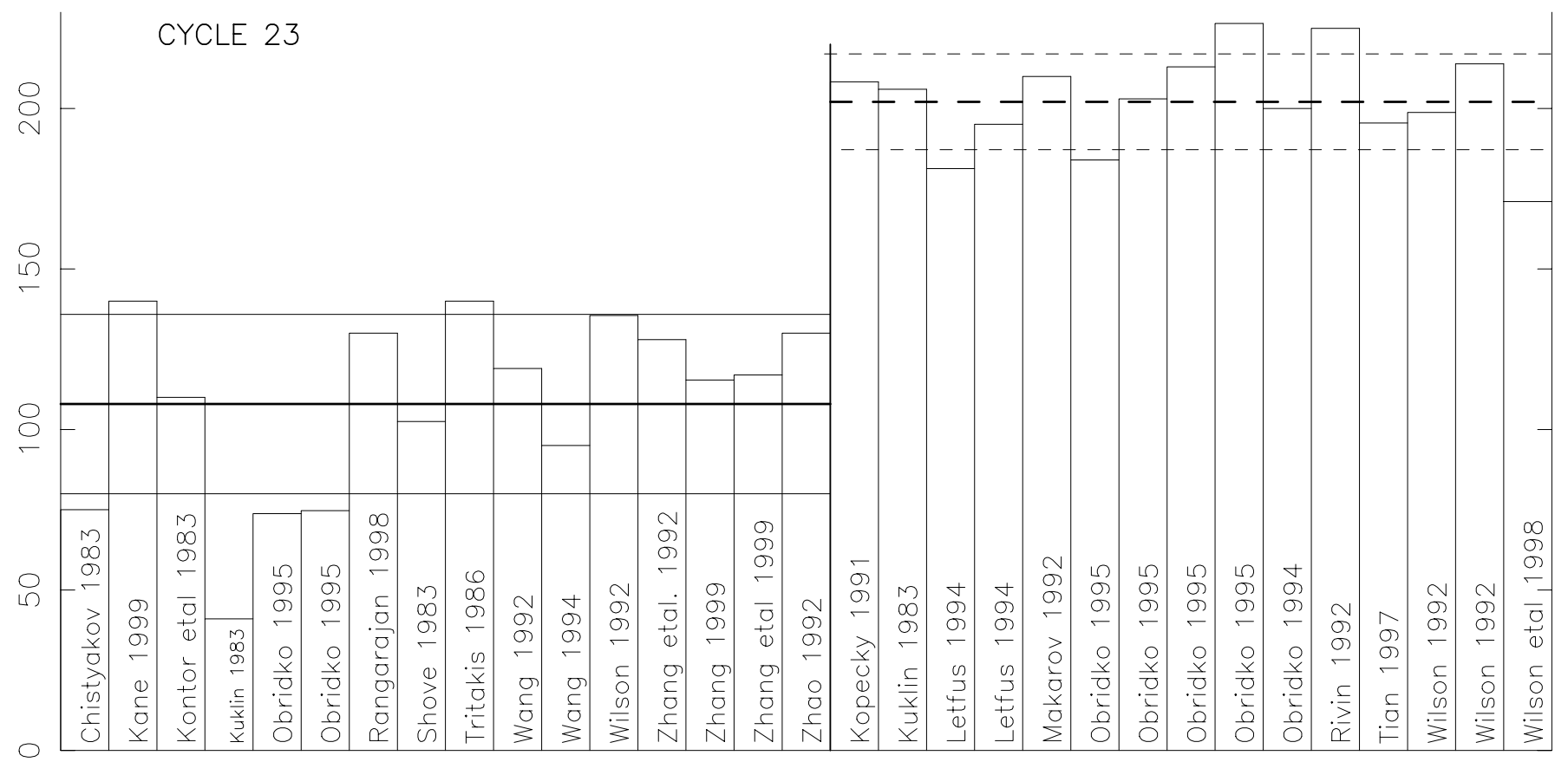

Fig. 4. Predictions of the maximum sunspot number of solar cycle 23 in Group A

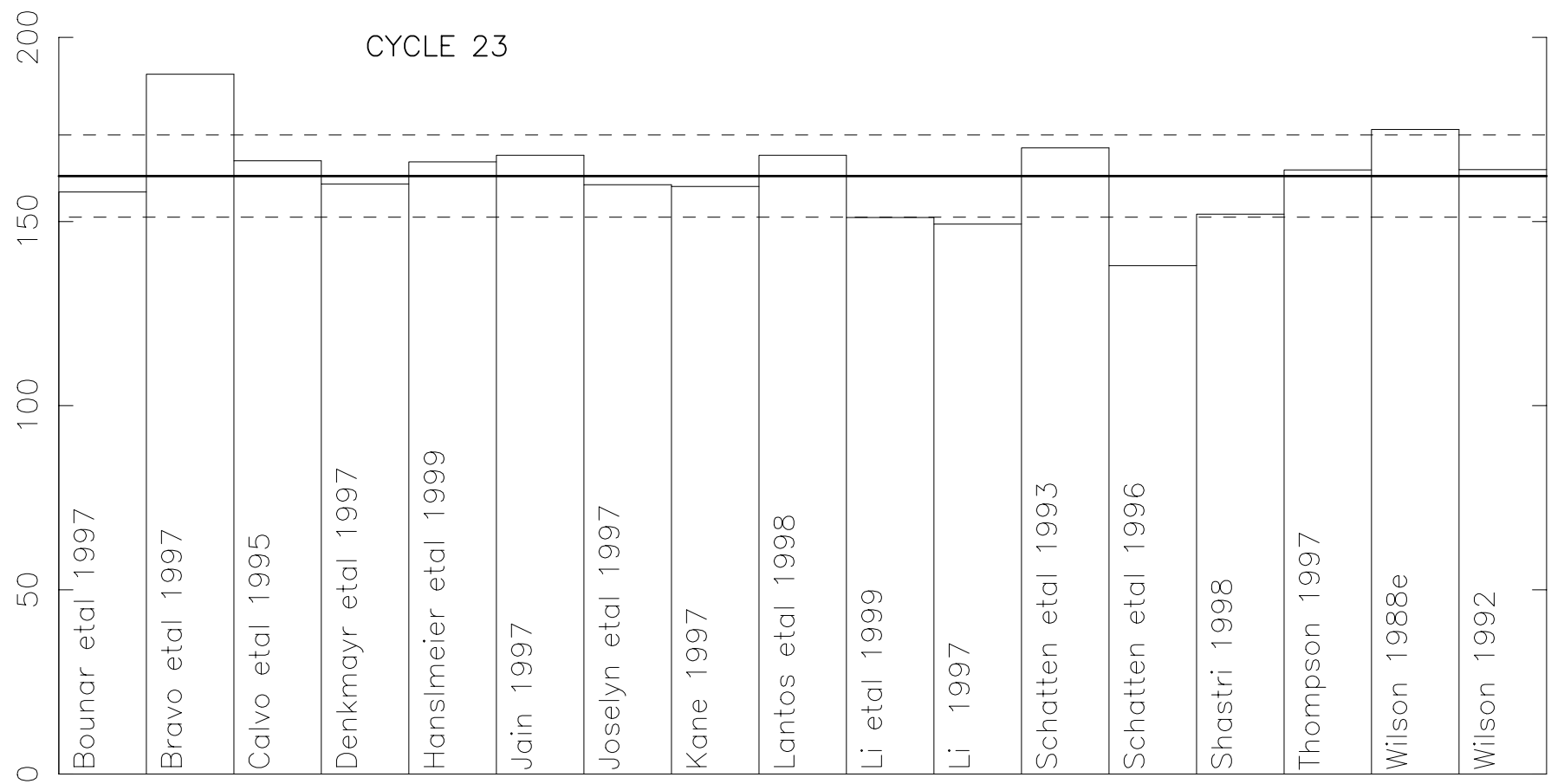

Fig. 5. Predictions of the maximum sunspot number of solar cycle 23 in Group B

average $\overline{R_{\mathrm{m}}}$ and the upper and lower bounds of $\overline{R_{\mathrm{m}}} \pm \sigma$ are presented in Fig. 4 where the horizontal solid lines refer to the first part with lower values and the horizontal dashed lines to the second part, respectively. As seen from Fig. 5, predictions of Group B surprisingly concentrate in a rather narrow interval with an average $\overline{R_{\mathrm{M}}}$ of 162.3 and a variance $\sigma$ of 11.2. Three lines representing average $\overline{R_{\mathrm{m}}}$ and the upper and lower bounds of $\overline{R_{\mathrm{m}}} \pm \sigma$ are also included in the figure.

\section{Conclusions and discussions}

In the present study we have collected values of maximum sunspot numbers of solar cycles 22 and 23 predicted by numerous workers and examined the characteristics of predictions made by various methods. A comparison is given based on predictions of the maxima of the sunspot numbers within solar cycles 21 to 23 , but the prediction dates of the maxima are not included in the present work, which 
is also an important criterion to assess the quality of solar activity predictions. Predictions for solar cycles 21 and 22 indicate that the precursor methods are always superior to other prediction methods. If this regularity should sustain in solar cycle 23 , the maximum sunspot number of cycle 23 should be around 162.3, the average of Group B for the solar cycle 23. When non-precursor methods were used, almost all of the predictions underestimate the observed maximum of solar activity for solar cycle 21 . What is more significant is that the predictions severely underestimate the maximum. For solar cycle 22, however most predictions underestimate the corresponding observed value of the maximum solar activity, but a few predictions overestimate observations. The starting time of solar cycle 23 is May 1996, and more than 4 years have already passed. We infer that probably the Sun should now be very close to the maximum of the activity, although the concrete date of the maximum activity is not known at present. The monthly sunspot number of recent several months (2000 Feb. to May) ranges from 112.3 to 138.2 , which resides in the middle of the two prediction averages of Group A, and they are close to the average of Group B. The observed maximum sunspot number of cycle 23 is confirmed to be much larger than the average of the first part of Group A. There is a very small probability for the maximum sunspot number to reach such a higher level of around the average 202.1 of Group B. According to the existing predictions made by non-precursor methods, the running tendency of solar activity of solar cycle 23 should either underestimate or overestimate the true maximum solar sunspot number and the ratio of overestimate-to-underestimate predictions increases to about one. This demonstrates again that precursor methods are by far more successful than other prediction methods, although at present we do not know if precursor methods completely succeed in the prediction of the maximum solar activity of cycle 23 . We made good progress in making predictions of the maximum solar activity of cycles 21 to 23 with the use of precursor methods. This may be due to improvement of the quality of observational data and/or it may be attributed to the fact that precursor methods are associated with the solar dynamo theory (Brown \& Simon 1986; Denkmayr 1993). As far as the accuracy of predictions is concerned, precursor methods are superior to non-precursor methods. However, precursor methods usually give a prediction just around the solar minimum within the range of a few years, while nonprecursor methods can make predictions ahead of time by a few years to several decades. A method to make predictions ahead of time on a larger time scale with high accuracy remains to be developed in the future.

Acknowledgements. The authors are indebted to Dr. Woehl for his helpful comments on this paper, and Dr. Katgert for improving the English. We would like to thank the staff of Solar Spectral Research Group of Yunnan Astronomical Observatory for their support and helps. This work was supported by the National Science Fundation of China, the Chinese Academy of Sciences, the Science Fundation of Yunnan Province, and the BK21 project of the Korean Government.

\section{References}

Berger, A., Goosen, C., \& Pestiaux, P. 1986, in SolarTerrestrial Predictions: Proceedings of a Workshop at Meudon, France, ed. P. A. Simon, G. Heckman, \& M. A. Shea (Published by NOAA/AFGL, USA), 13

Bounar, K. H., Cliver, E. W., \& Boriakoff, V. 1997, Solar Phys., 176, 211

Bravo, S., \& Stewart, G. A. 1997, Solar Phys., 173, 193

Brown, G. M., \& Simon, P. A. 1986, in Solar-Terrestrial Predictions: Proceedings of a Workshop at Meudon, France, ed. P. A. Simon, G. Heckman, \& M. A. Shea (Published by NOAA/AFGL, USA), 41

Brown, G. M. 1988, Nature, 333, 121

Brown, G. M. 1990, in Solar-Terrestrial Predictions: Proceedings of a Workshop at Leura, Australia, ed. R. J. Thompson (Published by NOAA/AFGL, USA), 309

Butcher, E. C. 1990, Geophys. Res. Lett., 17, 117

Calvo, R. A., Ceccato, H. A., \& Piacentini, R. D. 1995, ApJ, 444,916

Chistiakov, V. F. 1983, Solnechnye Dannye, 1, 97

Chistiakov, V. F. 1986, Solnechnye Dannye, 2, 97

Chistiakov, V. F. 1987, Solnechnye Dannye, 9, 71

Cohen, T. J., \& Lintz, P. R. 1974, Nature, 250, 398

Cole, T. W. 1973, Solar Phys., 30, 103

Denkmayr, K. 1993, On Long-Term Predictions of Solar Activity, Diploma Thesis, Lintz

Denkmayr, K. 1996, Solar Activity prediction Using Models Based on Solar Physics, Johannes Kepler Universitat, Lintz

Denkmayr, K., \& Cugnon, P. 1997, in Solar-Terrestrial Prediction V, Proc. of a Workshop at Hitachi, Japan, Jan. 1996, ed. G. Heckman, K. Maruboshi, M. A. Shea, D. F. Smart, \& R. Thompson, Communication Research Laboratory, Japan, 85

Gonzalez, G., \& Schatten, K. H. 1987, Solar Phys., 114, 189

Gregg, D. P. 1984, Solar Phys., 90, 185

Gregg, D. P. 1986, in Solar-Terrestrial Predictions: Proceedings of a Workshop at Meudon, France, ed. P. A. Simon, G. Heckman, \& M. A. Shea (Published by NOAA/AFGL, USA), 24

Hanslmeier, A., Denkmayr, K., \& Weiss, P. 1999, Solar Phys., 184,213

Harvey, K. L., \& White, O. R. 1999, J. Geophys. Res., 104, 19759

Hedeman, E. R., \& Dodson-Prince, H. 1986, in SolarTerrestrial Predictions: Proceedings of a Workshop at Meudon, France, ed. P. A. Simon, G. Heckman, \& M. A. Shea (Published by NOAA/AFGL, USA), 97

Hill, J. R. 1977, Nature, 266, 151

Holland, R. L., \& Vaughan, W. W. 1984, J. Geophys. Res., 89, 11

Hong, Q. F. 1992, Proceedings of the workshop on solar activity predictions, ed. Jia-Long Wang, Zu-Yan Zhu, \& Baorong Luo, 95

Hunter, H. E. 1979, in Solar-Terrestrial Predictions: Proceedings of a Workshop at Boulder, USA, ed. R. F. Donnelly, vol. 3, A22

Ivakhneuko, A. G., \& Sarychev, A. P. 1985, Sov. J. Autom. Inf. Sci., 18, 33

Jain, R. 1997, Solar Phys., 176, 431

Jia-Long, W., Bai-Sheng, T., \& Gui-Qing, Z. 1986, in SolarTerrestrial Predictions: Proceedings of a Workshop at Meudon, France, ed. P. A. Simon, G. Heckman, \& M. A. Shea (Published by NOAA/AFGL, USA), 99 
Joselyn, J. A., Anderson, J. B., Coffev, H., Harvey, K., \& Hathaway, D. 1997, Trans. Amer. Geophys. Union, 78, 205 Kane, R. P. 1987, Solar Phys., 108, 415

Kane, R. P. 1989, Solar Phys., 122, 175

Kane, R. P. 1992, Solar Phys., 140, 171

Kane, R. P. 1997, Geophys. Res. Lett., 24, 1899

Kane, R. P. 1999, Solar Phys., 189, 217

Kapoor, S. G., \& Wu, S. M. 1982, J. Geophys. Res., 87, 6

Kataja, E. I. 1986, in Solar-Terrestrial Predictions: Proceedings of a Workshop at Meudon, France, ed. P. A. Simon, G. Heckman, \& M. A. Shea (Published by NOAA/AFGL, USA), 35

Kerridge, D., Carlaw, V., \& Beamish, D. 1989, Development and Testing of Computer Algorithms for Solar and Geomagnetic Activity Forecasting, British Grological Survey, Technical Report WM/89/22C ESA CR(P) 3039

Kontor, N. N., Lyubimov, G. P., Pereslegina, N. V., \& Khotilovskaya, T. G. 1983, Solnechnye Dannye, 11, 74

Koons, H. C., \& Gorney, D. J. 1990, Trans. Amer. Geophys. Union, 71, 677

Kopecky, M. 1991, Bull. Astron. Inst. Czech., 42, 157

Kuklin, G. V. 1983, Solnechnye Dannye, 6, 61

Landscheidt, T., 1986, in Solar-Terrestrial Predictions: Proceedings of a Workshop at Meudon, France, ed. P. A. Simon, G. Heckman, \& M. A. Shea (Published by NOAA/AFGL, USA), 48

Lantos, P. 1990, in Solar-Terrestrial Predictions: Proceedings of a Workshop at Leura, Australia, ed. R. J. Thompson (Published by NOAA/AFGL, USA), 118

Lantos, P., \& Richard, O. 1998, Solar Phys., 182, 231

Layden, A. C., Fox, P. A., Howard, J. M., Sarajedim, A., \& Schatten, K. H. 1991, Solar Phys., 132, 1

Letfus, V. 1994, Solar Phys., 149, 405

Li, K. J., \& Gu, X. M. 1999, A\&A, 348, L59

Li, Y. 1997, Solar Phys., 170, 437

Makarov, V. I. 1986, Solnechnye Dannye, 8, 57

Makarov, V. I., Makarova, V. V., \& Sivaraman, K. R. 1989, Solar Phys., 119, 45

Makarov, V. I., \& Mikhailutsa, V. P., 1992, Solar Phys., 137, 385

McIntosh, P. S., Brown, G. M., Buhmann, R., et al. 1979, in Solar-Terrestrial Predictions: Proceedings of a Workshop at Boulder, USA, ed. R. F. Donnelly, vol. 2, 246

McNish, A. G., \& Lincoln, J. V. 1949, Trans. Amer. Geophys. Union, 30, 673

Mingchan, W. 1986, in Solar-Terrestrial Predictions: Proceedings of a Workshop at Meudon, France, ed. P. A. Simon, G. Heckman, \& M. A. Shea (Published by NOAA/AFGL, USA), 103

Nagovitsin, Yu. A. 1988, Solnechnye Dannye, 8, 88

Ohl, A. I. 1987, Solnechnye Dannye, 2, 58

Obridko, V. N. 1988, Solnechnye Dannye, 11, 106

Obridko, V. N. 1995, Solar Phys., 156, 179

Obridko, V. N., Oraevsky, V. N., \& Allen, J. H. 1994, in Proc. of the 1992 STEP Symposium/5th COSPAR Colloquium, held in Laurel, Maryland, USA, 24-28 August, 1992, ed. D. N. Baker, V. O. Papitashvili, \& M. J. Teague, 557

Otaola, J. A., \& Zenteno, G. 1983, Solar Phys., 89, 209

Rangarajan, G. K. 1998, Earth Planets Space, 50, 91

Rivin, Yu. R. 1992, The Forecast of Unusually High Values of Solar Activity at the End of the Current Century and its Discussion, in Cycles of Natural Processes, Dangerous Phenomena, and Exological Forecasting, MNTK Geos, Moscow, 1992, 144
Sargent, H. H. 1977, Trans. Amer. Geophys. Union, 58, 1220

Schatten, K. H., \& Hedin, A. E. 1984, Geophys. Res. Lett., 11, 873

Schatten, K. H., Myers, D. J., \& Sofia, S. 1996, Geophys. Res. Lett., 23, 605

Schatten, K. H., \& Pesnell, W. D. 1993, Geophys. Res. Lett., 20,2275

Schatten, K. H., \& Sofia, S. 1987, Geophys. Res. Lett., 14, 732

Schove, D. J. 1955, J. Geophys. Res., 60, 127

Shastri, S. 1998, Solar Phys., 180, 499

Shastri, S. K. S., Aggarwal, S., \& Raddy, B. M. 1990, in Solar-Terrestrial Predictions: Proceedings of a Workshop at Leura, Australia, ed. R. J. Thompson (Published by NOAA/AFGL, USA), 566

Shove, D. J. 1983, Ann. Geophys., I, 391

Smith, P. A. 1986, in Solar-Terrestrial Predictions: Proceedings of a Workshop at Meudon, France, ed. P. A. Simon, G. Heckman, \& M. A. Shea (Published by NOAA/AFGL, USA), 8

Suda, T. 1979, in Solar-Terrestrial Predictions: Proceedings of a Workshop at Boulder, USA, ed. R. F. Donnelly, vol. 3, A96

Thompson, R. 1985, Recurrent Geomagnetic Disturbances in 53 Years of Ap Indices, IPS technical Report IPS-TR-8506, IPS Radio and Space Services, Darlinghurst, Australia

Thompson, R. J. 1997, in Solar-Terrestrial Prediction V, Proc. of a Workshop at Hitachi, Japan, Jan. 1996, Communication Research Laboratory, Japan, ed. G. Heckman, K. Maruboshi, M. A. Shea, D. F. Smart, \& R. Thompson, 115

Tian, J. 1997, in Solar-Terrestrial Prediction V, Proc. of a Workshop at Hitachi, Japan, Jan. 1996, Communication Research Laboratory, Japan, ed. G. Heckman, K. Maruboshi, M. A. Shea, D. F. Smart, \& R. Thompson, 129

Tritakis, V. P. 1982, Astrophys. Space Sci., 82, 463

Tritakis, V. P. 1986, in Solar-Terrestrial Predictions: Proceedings of a Workshop at Meudon, France, ed. P. A. Simon, G. Heckman, \& M. A. Shea (Published by NOAA/AFGL, USA), 106

Vitinsky, Yu. I. 1986, Solnechnye Dannye, 8, 64

Wang, J. L. 1992, Proceedings of the workshop on solar activity predictions, Sep. 19-23, 1991, Suzhou, China, ed. J. L. Wang, Z. Y. Zhu, \& B. R. Luo, 23

Wang, J. L. 1994, Progress in Geophysics (Chinese), Special Issue, 1

Wilson, R. M. 1988a, Solar Phys., 115, 397

Wilson, R. M. 1988b, J. Geophys. Res., 93, 10011

Wilson, R. M. 1988c, Geophys. Res. Lett., 15, 125

Wilson, R. M. 1988d, Nature, 335, 773

Wilson, R. M. 1988e, Solar Phys., 117, 269

Wilson, R. M. 1992, Solar Phys., 140, 181

Wilson, R. M., Hathaway, D. H., \& Reichmann, E. J. 1998, J. Geophys. Res., 103, 6596

Wilson, R. M., Reichman, E. J., \& Teuber, D. L. 1986, in Solar-Terrestrial Predictions: Proceedings of a Workshop at Meudon, France, ed. P. A. Simon, G. Heckman, \& M. A. Shea (Published by NOAA/AFGL, USA), 26

Xanthakis, J. N., \& Poulakos, C. 1986, in Solar-Terrestrial Predictions: Proceedings of a Workshop at Meudon, France, ed. P. A. Simon, G. Heckman, \& M. A. Shea (Published by NOAA/AFGL, USA), 118 
Xu, Z. T., Zhao, A. D., Mei, Y. L., \& Guo, Q. S. 1979, in Solar-Terrestrial Predictions: Proceedings of a Workshop at Boulder, USA, ed. R. F. Donnelly, vol. 1, 163

Yule, G. U. 1927, On a method of investigating periodicities in disturbed series, with special reference to Wolfer's numbers, Phil. Trans. R. Soc. London A, 226, 267

Zhang, G. Q., Nan, K., Xiang, J. T., \& Wang, J. L. 1992, Proceedings of the workshop on solar activity predictions, Sep. 19-23, 1991, Suzhou, China, ed. J. L. Wang, Z. Y. Zhu,
\& B. R. Luo, 19

Zhang, G. Q. 1999, Acta Astrophys. Sin. (Chinese), 19, 227 Zhang, G. Q., \& Wang, H. N. 1999, Solar Phys., 188, 397

Zhao, A. D. 1992, Proceedings of the workshop on solar activity predictions, Sep. 19-23, 1991, Suzhou, China, ed. J. L. Wang, Z. Y. Zhu, \& B. R. Luo, 28

Zhong, Q. 1990, in Solar-Terrestrial Predictions: Proceedings of a Workshop at Leura, Australia, ed. R. J. Thompson (Published by NOAA/AFGL, USA), 685 